Albert Baumgarten

\title{
Elias Bickerman as a Historian of the Jews
}

\section{A Twentieth Century Tale}

[Elias Bickerman als Historiker der Juden. Eine Geschichte des 20. Jahrhunderts.]

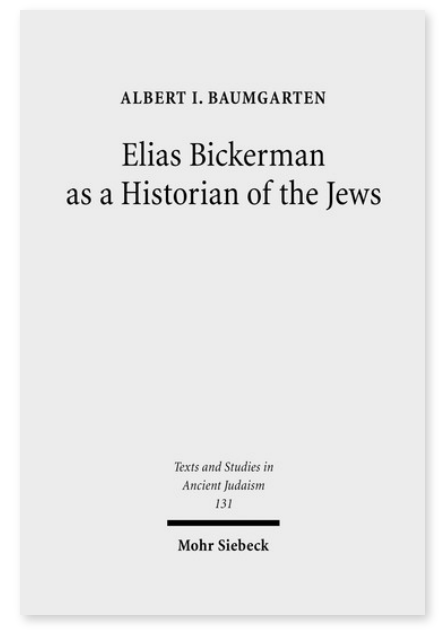

2010. X, 377 Seiten. TSAJ 131

ISBN 978-3-16-151464-7

DOI 10.1628/978-3-16-151464-7

eBook PDF 129,00€

ISBN 978-3-16-150171-5

Leinen $129,00 €$
Veröffentlicht auf Englisch.

Die vorliegende Biographie über Elias Bickerman (1897-1981), einem der führenden Historiker der griechisch-römischen Antike, konzentriert sich auf seine Rolle als Historiker der Juden. Bickerman führte ein außergewöhnliches Leben. Er wurde in Kishinev geboren und wuchs in St. Petersburg auf. 1922 kam er nach Berlin, wo er eine akademische Karriere verfolgte (Promotion 1926, Habilitation 1930). Mit dem Emporkommen der Nazionalsozialisten zog er 1933 nach Paris, 1942 in die USA. Er starb in Tel Aviv und wurde in Jerusalem beerdigt.

Albert Baumgarten untersucht die Verbindungen zwischen Bickermans Leben und seiner Forschung über Juden in ihren verschiedenen kulturellen und akademischen Kontexten (russisch, deutsch, französisch und amerikanisch). Bickerman verfolgte die Absicht, eine nutzbare jüdische Vergangenheit zu entwerfen. Es wird gezeigt, daß er die Begegnung der frühen Juden mit dem Hellenismus und den neuzeitlichen Entritt der Juden in die europäische Zivilisation in Beziehung zueinander setzt.

Albert Baumgarten Born 1942; 1972 PhD Columbia University; currently Professor of Jewish History at Bar Ilan University, Ramat Gan, Israel.
Jetzt bestellen:

https://mohrsiebeck.com/buch/elias-bickerman-as-a-historian-of-the-jews-9783161514647?no_cache=1 order@mohrsiebeck.com

Telefon: +49 (0)7071-923-17

Telefax: $+49(0) 7071-51104$ 